\title{
DISTRIBUIÇÃO ESPACIAL DE FORMAÇÕES SUPERFICIAIS GENETICAMENTE ASSOCIADAS A ROCHAS SILICICLÁSTICAS - PLANALTO DO ESPINHAÇO MERIDIONAL (MG) - BRASIL
}

\section{Spatial distribution of genetically superficial formations associated with siliciclastic rocks - Plateau of Southern Espinhaço (MG) - Brazil}

Patrícia Mara Lage Simões patricia.simoes@cprm.gov.br CPRM - Serviço Geológico do Brasil

Roberto Célio Valadão valadaobh@gmail.com

Universidade Federal de Minas Gerais, Belo Horizonte, Minas Gerais, Brasil

Cristiane Valéria de Oliveira crisval_oliveira@yahoo.com.br Universidade Federal de Minas Gerais, Belo Horizonte, Minas Gerais, Brasil

Fábio Soares de Oliveira fabiosolos@gmail.com Universidade Federal de Minas Gerais, Belo Horizonte, Minas Gerais, Brasil

Politácito Santos politacito@gmail.com Universidade Federal de Minas Gerais, Belo Horizonte, Minas Gerais, Brasil

RESUMO: A área de estudo que se situa na borda oeste do Planalto do Espinhaço Meridional, na qual predominam as rochas siliciclásticas que integram unidades geológicas diversas, observaram-se dois tipos distintos de padrões de distribuição da formação superficial, linear e zonal. Este trabalho objetiva analisar essa distribuição espacial das formações superficiais de trecho do Planalto do Espinhaço Meridional localizado no alto curso do Rio Pardo Pequeno (MG), discutindo o papel exercido pela organização litoestrutural na espacialidade dessa cobertura pedológica. Para executar tal investigação foram produzidos mapas de distribuição espacial das formações superficiais, mapa de estrutura geológica, e perfis topográficos e geológicos. As formações superficiais verificadas na área de estudo apresentam uma distribuição espacial essencialmente conduzida pelas características do arcabouço estrutural e litológico da região. A distribuição linear relaciona-se às feições estruturais, como: falhas, falhas de empurrão, alinhamentos, anticlinais e

DOI: http://dx.doi.org/10.1590/1982-451320160111 
sinclinais. Já as formações zonais são influenciadas pelas diferenças entre a resistência das diversas rochas aos processos intempéricos. $\mathrm{O}$ estudo das características das formações superficiais e suas associações com os aspectos litoestruturais são essenciais para compreender a configuração geomorfológica do alto curso do Rio Pardo Pequeno.

Palavras-chave: Formação superficial, geomorfologia estrutural, pedologia

\begin{abstract}
The study area which lies on the western edge of the Southern Highlands Ridge, are predominant in siliciclastic rocks that integrate different geological units, we observed two distinct types of distribution patterns of shallow, linear and zonal training. This work aims to analyze the spatial distribution of surface formations stretch from the Southern Espinhaço Plateau located in the upper reaches of the Rio Pardo Small (MG), discussing the role played by the organization in litoestrutural spatiality of this soil cover. To perform such an investigation of spatial distribution maps of surface formations, geological structure map, and topographical and geological profiles were produced. The superficial formations observed in the study area have a spatial distribution essentially driven by the characteristics of the lithological and structural framework of the region. The linear distribution is related to structural features, such as faults, thrust faults, alignments, anticlines and synclines. Already zonal formations are influenced by differences between the resistance of different rocks to weathering processes. The study of the characteristics of surface formations and their associations with lithostructural aspects are essential to understand the geomorphic setting of the upper reaches of the Rio Pardo Small.
\end{abstract}

Keywords: Surface formation, structural geomorphology, pedology

\section{INTRODUÇÃO}

A bacia do alto Rio Pardo Pequeno está localizada no Planalto do Espinhaço Meridional/ MG, modelado em uma faixa móvel de idade neoproterozóica. As superfícies de cimeira desse planalto alcançam altimetria de até 1400 metros, a partir da qual relevos residuais se elevam e atingem, por vezes, pouco mais de 2.000 metros de altitude. Com direção geral norte-sul, esse conjunto de terras elevadas se destaca no cenário regional do Sudeste brasileiro como um importante divisor hidrográfico das bacias dos rios São Francisco, Jequitinhonha e Araçuaí (Figura 01). O arcabouço litoestrutural desse extenso planalto remonta longa história evolutiva cujos estágios finais tiveram lugar entre o final do neoproterozóicoeo Cambriano(650-500MA), quando esforços compressivos resultaram em um conjunto complexo de falhas, dobras e cavalgamentos que deformaram espessa sequência vulcano-sedimentar (ABREU, 1995; ABREU; RENGER, 2002; DUSSIN; DUSSIN,1995; RENGER; KNAUER, 1995). Ao longo do fanerozóico, transcorridos cerca de 500 MA, a profunda denudação dessa faixa móvel expôs, na atualidade, volumes litoestratigráficos em que há, em trechos extensos do planalto, o predomínio de rochas siliciclásticas - notadamente os quartzitos. 
Figura 01 - Contexto locacional da bacia do alto Rio Pardo Pequeno

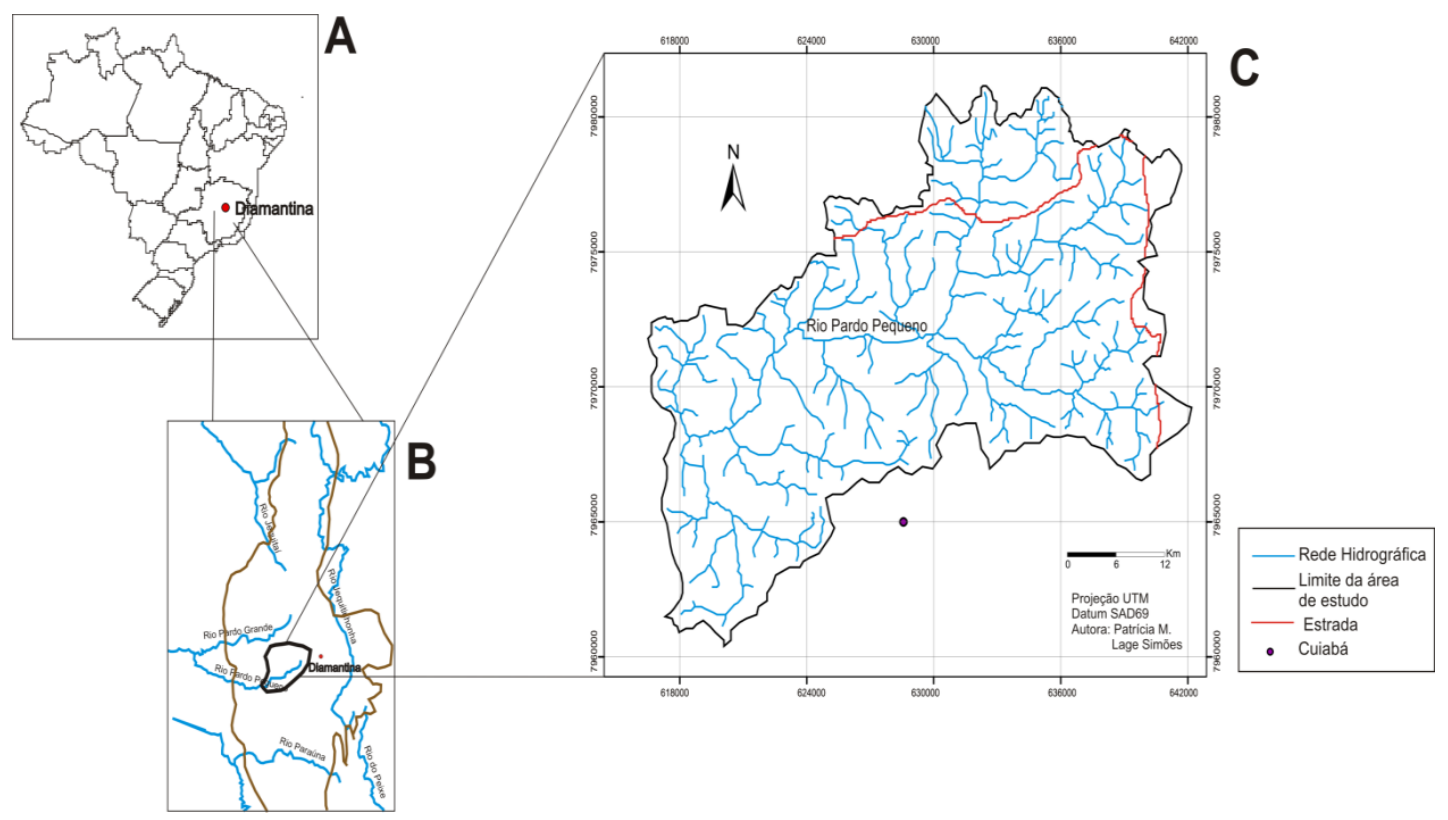

A: Localização da cidade de Diamantina no Estado de Minas Gerais; a área investigada neste trabalho está localizada a oeste de Diamantina;

B: Delimitação da bacia do alto Rio Pardo Pequeno no Planalto do Espinhaço Meridional; observe a posição desse planalto como divisor hidrográfico regional entre as bacias dos rios Paraúna, Pardo Pequeno, Pardo Grande e Jequitaí, a oeste, e as bacias do Rio do Peixe e Jequitinhonha, a leste.

C: Rede hidrográfica da bacia do alto Rio Pardo Pequeno.

Fonte: IBGE,2010

Autor: Simões, P. M. L.

É nesse contexto que se insere a área investigada neste trabalho, em que predominam as rochassiliciclásticasqueintegramunidadesgeológicas diversas (as formações Galho do Miguel, Sopa Brumadinho, São João da Chapada e o Grupo Costa Sena indiviso), litoestratigraficamente pertencentes ao Supergrupo Espinhaço. Essas rochas apresentam alta resistência aos processos intempéricos, uma vez que há em sua composição elevado percentual de sílica, elemento de alta estabilidade e baixa solubilidade (PATTON, 1978; FABRI et al., 2014; SALGADO; VALADÃO, 2003; REZENDE et al., 2010). Apesar desse fato, em regiões tropicais úmidas, como no caso da área de estudo, é evidente a influência de processos geoquímicos de dissolução na formação das feições do relevo. Apesar das rochas quartzíticas serem significativamente resistentes aos processos químicos, não há impedimento que ocorra a formação de feições geomorfológicas mediante contribuição da dissolução geoquímica. Essa contribuição tem se verificado na prática mais relevante do que se considera em alguns trabalhos, notadamente naqueles ambientes em que é intensa a percolação da água (YOUNG; YOUNG, 1992). Além da área de estudo se inserir em ambiente bioclimático favorável à ocorrência de processos geoquímicos na gênese do relevo (THOMAS, 1994), a análise de cartas geológicas em escalas diversas tem demonstrado que a estrutura geológica presente na região exerce significativa influência no desenvolvimento e distribuição das formações superficiais, como já foi evidenciado por Barbosa et al. (2009) e Santos (2012).

Diante dessa perspectiva, tem-se como objetivo analisar a distribuição espacial das formações superficiais de trecho do Planalto do 
Espinhaço Meridional localizado no alto curso do Rio Pardo Pequeno (MG), buscando-se discutir acerca do condicionamento exercido pela organização litoestrutural na espacialidade da cobertura pedológica e de demais volumes inconsolidados dela derivados. Importante salientar que, neste trabalho, adota-se o conceito de formação superficial proposto por Campy; Macaire (1989), a saber: camada superficial e subsuperficial, posicionada no limite entre a litosfera e a atmosfera, que abrange tanto materiais alterados in situ, que passaram por processos de pedogênese, como também materiais transportados e depositados em resposta à dinâmica geomorfológica.

\section{MATERIAIS E MÉTODOS}

Com vistas a analisar o condicionamento da organização litoestrutural no desenvolvimento e distribuição das formações superficiais, adotou-se técnicas de análise cartográfica em consonância com investigações de campo.

$\mathrm{Na}$ etapa de gabinete foram analisadas cartas topográficas (FOLHA DIAMANTINA; IBGE, 1977) e geológicas (FOLHA DIAMANTINA; COMIG, 1996), ambas na escala 1:100.000, nas quais se reconheceu superfícies de altimetria elevada marcadas por baixo gradiente de dissecação que se destacam na configuração topográfica regional; essas superfícies, a princípio, não apresentaram relação clara com a organização litoestrutural regional, uma vez que seu revestimento por formações superficiais se revelou capaz de obliterar condicionantes derivados da resistência diferenciada das rochas aos processos intempéricos e da influência de possíveis descontinuidades estruturais.

As formações superficiais foram mapeadas a partir de imagens rapideye de 2010, cedidas pelo Instituto Estadual de Floresta - MG, por meio do emprego do software arcgis 9.3. Durante esse mapeamento se verificou que a espacialidade dessas formações se distingue marcadamente pela ocorrência de dois padrões espaciais, aquele cuja distribuição é linear, e aquele zonal.

Essa marcante distinção quanto à distribuição espacial das formações superficiais se revelou indicadora do condicionamento litoestrutural que, durante investigações iniciais, não foi prontamente reconhecido, por razões já explicitadas. Diante dessa perspectiva, foi gerado mapa estrutural da área de estudo a partir do banco de dados disponibilizado pelo Projeto Espinhaço (COMIG, 1996). Para subsidiar a investigação da relação entre a distribuição espacial das formações superficiais e a estrutura geológica foram confeccionadas, a partir do mapeamento geológico do Projeto Espinhaço (COMIG, 1996), três seções geológicas que representam, em perfil, o arcabouço geológico fundamental da área investigada segundo as direções WNW-ESE, W-E e WSW-ENE.

As investigações de campo ocorreram em três etapas distintas. A primeira delas esteve voltada para o reconhecimento da área investigada, com objetivo de se registrar suas feições geomorfológicas fundamentais, como subsídio ao planejamento das etapas de campo e gabinete posteriores. Na segunda etapa de campo os recortes espaciais revestidos por formações superficiais, já então reconhecidos e preliminarmente mapeados por meio uso de imagens orbitais, tiveram sua organização geomorfológica e morfométrica descritas em detalhe; esforços mais sistemáticos se destinaram a verificar os limites desses recortes espaciais, os quais se dão, notadamente, com afloramentos de rochas siliciclásticas altimetricamente posicionados acima ou abaixo das manchas revestidas por formações superficiais. $\mathrm{Na}$ terceira etapa de campo a distribuição espacial das formações superficiais foi ajustada segundo sua expressão na paisagem.

Os mapeamentos realizados e as seções geológicas, postos em diálogo com o cenário geomorfológico da área investigada, possibilitaram a análise da relação entre a distribuição espacial das formações superficiais do alto curso do Rio Pardo Pequeno com a estrutura geológica de trecho do Planalto do Espinhaço Meridional.

\section{DISTRIBUIÇÃO ESPACIALDAS FORMAÇÕES SUPERFICIAIS}

A gênese e o desenvolvimento das formações superficiais se relacionam com elementos tipicamente pedogenéticos e morfodinâmicos, que comumente envolvem vasta e complexa gama de processos 
(alteração geoquímica, erosão, transferência gravitacional de massa, sedimentação); por essa razão, constituem-se comumente por materiais inconsolidados de tipologia diversificada. É nesse contexto que se inserem os diversos materiais que compõem as formações superficiais reconhecidas e mapeadas neste trabalho, notadamente na bacia do alto Rio Pardo Pequeno. A área mapeada é marcada, em planta, pela alternância espacial entre formações superficiais e afloramentos rochosos, estes últimos ocupando vasta distribuição (Figuras 02 e 03).

$\mathrm{Na}$ área investigada as formações superficiais ocorrem em padrão de distribuição espacial linear e zonal (Figura 3). O padrão linear ocupa, via de regra, faixas estreitas (largura máxima aproximada de até 250 metros) que se estendem ao longo dos principais canais fluviais sem, contudo, corresponderem exclusivamente a aluviões. Todavia, verifica-se também esse padrão em posição outra que não em fundos de vale, independentemente da proximidade de linhas de talvegue. O padrão zonal, apesar de congregar aqueles recortes espaciais das formações superficiais que se expressam na forma de manchas, denota em planta geometria diversificada. Essas manchas apresentam dimensões variadas, por vezes alcançando pouco mais de 2,5 quilômetros de extensão em seu maior eixo, não revelando em planta contornogeométricoespecífico. Suas bordas assumem acentuada irregularidade e a porção mediana de cada mancha é comumente drenada por canais fluviais de primeira, segunda e terceira ordens. Nessas manchas, rampas revestidas por formações superficiais arenosas com espessura de até 3 metros, convergem em direção às principais linhas de talvegue, cujos perfis longitudinais são também caracterizados pelo gradiente baixo, sendo raros knick points, rápidos e corredeiras. Naquelas áreas em que o padrão de distribuição espacial das formações superficiais é linear, os perfis longitudinais dos canais fluviais são marcados por numerosas rupturas de declive, sendo comuns trechos encachoeirados.

Figura 02: Configuração geomorfológica de trecho da bacia do alto Rio Pardo Pequeno (Planalto do Espinhaço Meridional/MG).

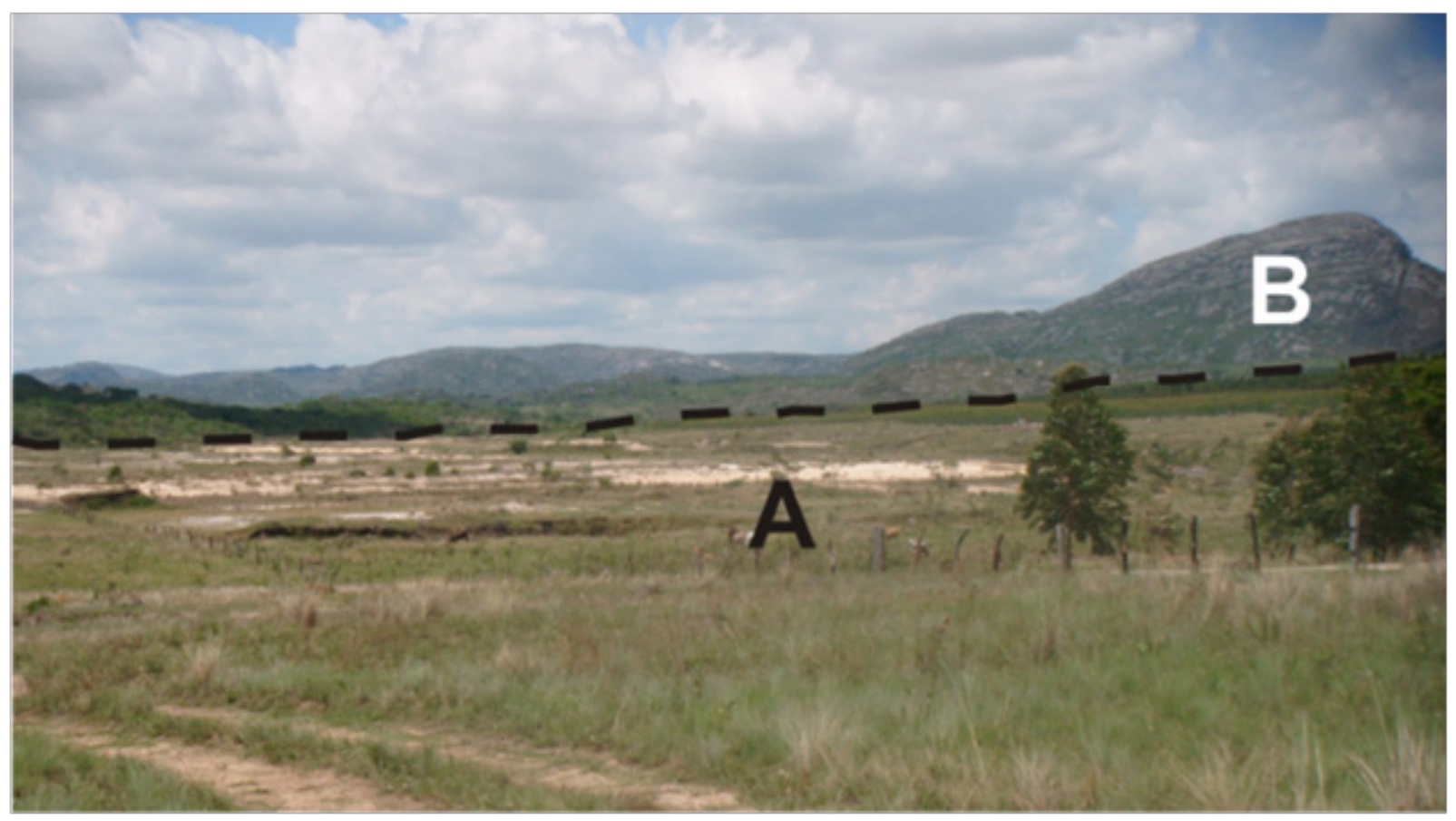

(A): rampas de baixo gradiente revestidas por formações superficiais;

(B): elevações residuais cuja morfometria é fortemente controlada pelo arcabouço geológico. 
Os afloramentos rochosos, na Figura 03, correspondem, sobretudo, a rochas siliciclásticas, bem como as formações superficiais estão geneticamente associadas a elas. Nesse mapa (Figura 03), a linha pontilhada delimita os recortes espaciais em que predomina a distribuição espacial linear (A) e zonal (B) das formações superficiais.

Figura 03: Distribuição espacial das formações superficiais da bacia hidrográfica do alto Rio Pardo Pequeno (Planalto do Espinhaço Meridional/MG).

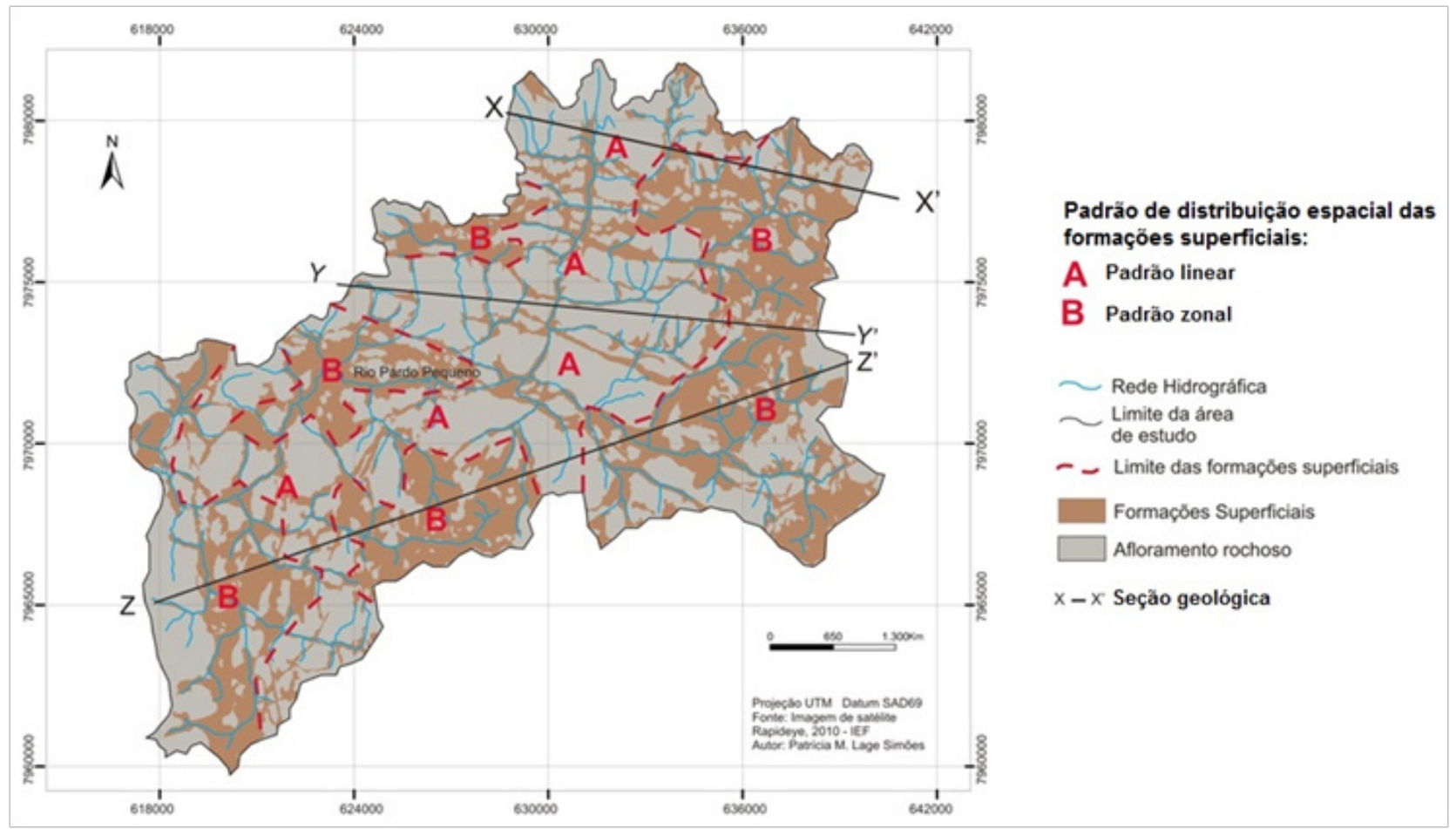

Fonte: Imagem de satélite rapideye 2010 - IEF

Autor: Simões, P. M. L.

O padrão linear ocorre associado ao zonal em parcela considerável da extensão da bacia hidrográfica mapeada, com exceção de larga faixa de orientação norte-sul que ocupa posição centro-leste. Ao longo dessa faixa, há claro o predomínio do padrão linear, enquanto o padrão zonal está praticamente ausente. Essa variabilidade da distribuição espacial das formações superficiais está em grande parte condicionada ao arcabouço litoestrutural vigente na bacia do alto Rio Pardo Pequeno, aspecto esse discutido no item que se segue.

\section{ARCABOUÇOGEOLÓGICOEVARIABILIDADE ESPACIAL DAS FORMAÇÕES SUPERFICIAIS NA BACIA DO ALTO RIO PARDO PEQUENO: RELAÇÕES POSSÍVEIS}

O arcabouço geológico da bacia do alto Rio PardoPequenoreproduzaquelevigenteemgrandeparte do Planalto do Espinhaço Meridional, caracterizado por estruturas geológicas de alcance regional associadas à espessa sequência de empilhamento de nappes de cavalgamento e dobramentos de idade brasiliana, com vergência predominante para oeste e direção geral norte-sul dos planos axiais e de eixos sinclinais e anticlinais (Figura 04). Esses dobramentos e nappes são entrecortados por falhas de empurrão e outras tipologias de descontinuidades lineares, com destaque para fraturas, falhas de rejeito vertical e falhas transcorrentes. Nesse quadro estrutural se destacam algumas direções derivadas de eventos pré-cambrianos: os empurrões e dobras $\mathrm{N}-\mathrm{S}$, as falhas de transferência WNW-ESE e NW-SE, 
as falhas NE-SW e, ainda, as transcorrências E-W (Saadi, 1995). Na porção meridiana, no limite do Cráton São Francisco com a faixa de dobramento, o escarpamento da borda oeste se configura como um front de cavalgamento, em que no bloco superior se posicionam os quartzitos do Supergrupo Espinhaço e, no bloco inferior, os metassedimentos dos grupos Macaúbas e Bambuí (OLIVEIRA; ALKMIN, 1994). Knauer (2007) descreve a estrutura regional dessa área como um sistema de falhas inversas ou de empurrão, que apresenta planos direcionados para sul, com mergulhos moderados e altos na porção leste. Esse mesmo autor registra ainda a presença de blocos maiores com ocorrência de grandes dobras abertas até fechadas, quase sempre assimétricas, com eixo aproximado norte-sul.

$\mathrm{Na}$ Figura 04, pode-se observar que as estruturas vinculadas à deformação rúptil apresentam, em planta, orientação predominante WNW-ESSE, NW-SE e NE-SW, ao passo que as direções N-S se associam ao caráter deformacional dúctil.

Figura 04: Elementos estruturais principais presentes no arcabouço geológico da bacia hidrográfica do alto Rio Pardo Pequeno (Planalto do Espinhaço Meridional/MG).

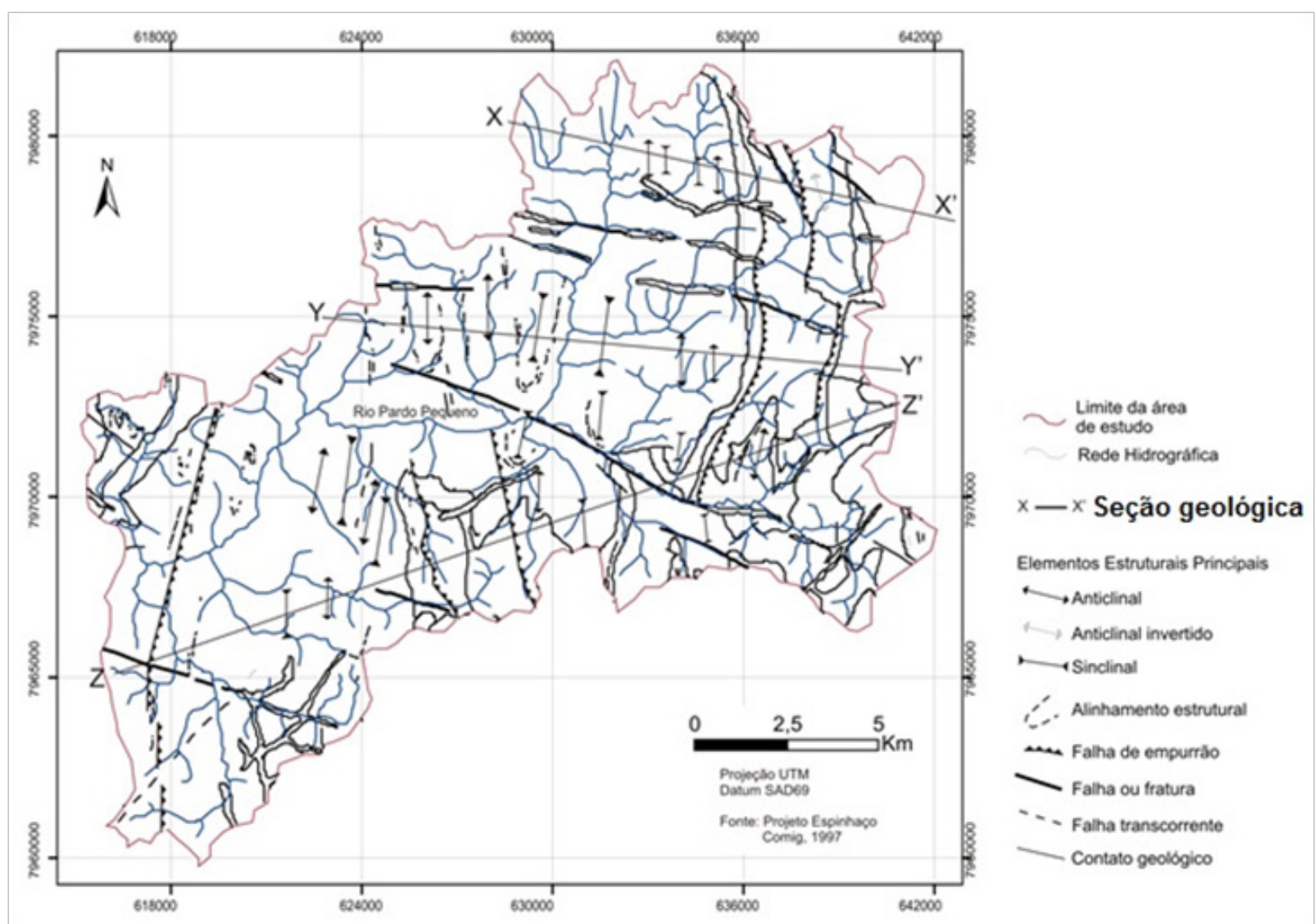

Fonte: Projeto Espinhaço, Comig, 1997

Autor: Simões, P. M. L.

A análise comparada entre os elementos estruturais principais e a distribuição espacial das formações superficiais demonstra marcante condicionamento dos primeiros sobre o padrão espacial linear dessas últimas (Figuras 03 e 04). Esse padrão linear se mostra condicionado, sobretudo: (i) pelas falhas e fraturas WNW-ESSE, notadamente nas porções central e noroeste da área investigada, onde controlam segmentos extensos dos canais fluviais; (ii) pelos eixos anticlinais e sinclinais N-S presentes 
na porção central, onde afloramentos extensos de quartzitos que sustentam relevos residuais sealternam, em planta, com formações superficiais dispostas em faixas que alcançam até cerca de 6 quilômetros de extensão, por vezes interrompidas e seccionadas por falhas de empurrão e de transcorrência.

Seções geológicas regionais justapostas às informações acerca da ocorrência ou não de formações superficiais (Figura 05), expressam de modo satisfatório a relação dessas últimas com a variabilidade litológica presente na área investigada.
Nessecontexto,édigno denota aescassezde formações superficiais naquelas áreas cujo arcabouço litológico é composto por quartzitos puros, de granulação fina, pertencentes à Formação Galho do Miguel. As raras ocorrências de formações superficiais sobre essas rochas se restringem a fundo de vales, notadamente aluviões, cujo padrão de distribuição espacial é aquele linear. A ocorrência de maior continuidade de formações superficiais está associada à presença das rochas graníticas. A localização dessas seções é mostrada na Figura 4.

Figura 05: Distribuição das formações superficiais ao longo de seções geológicas regionais.

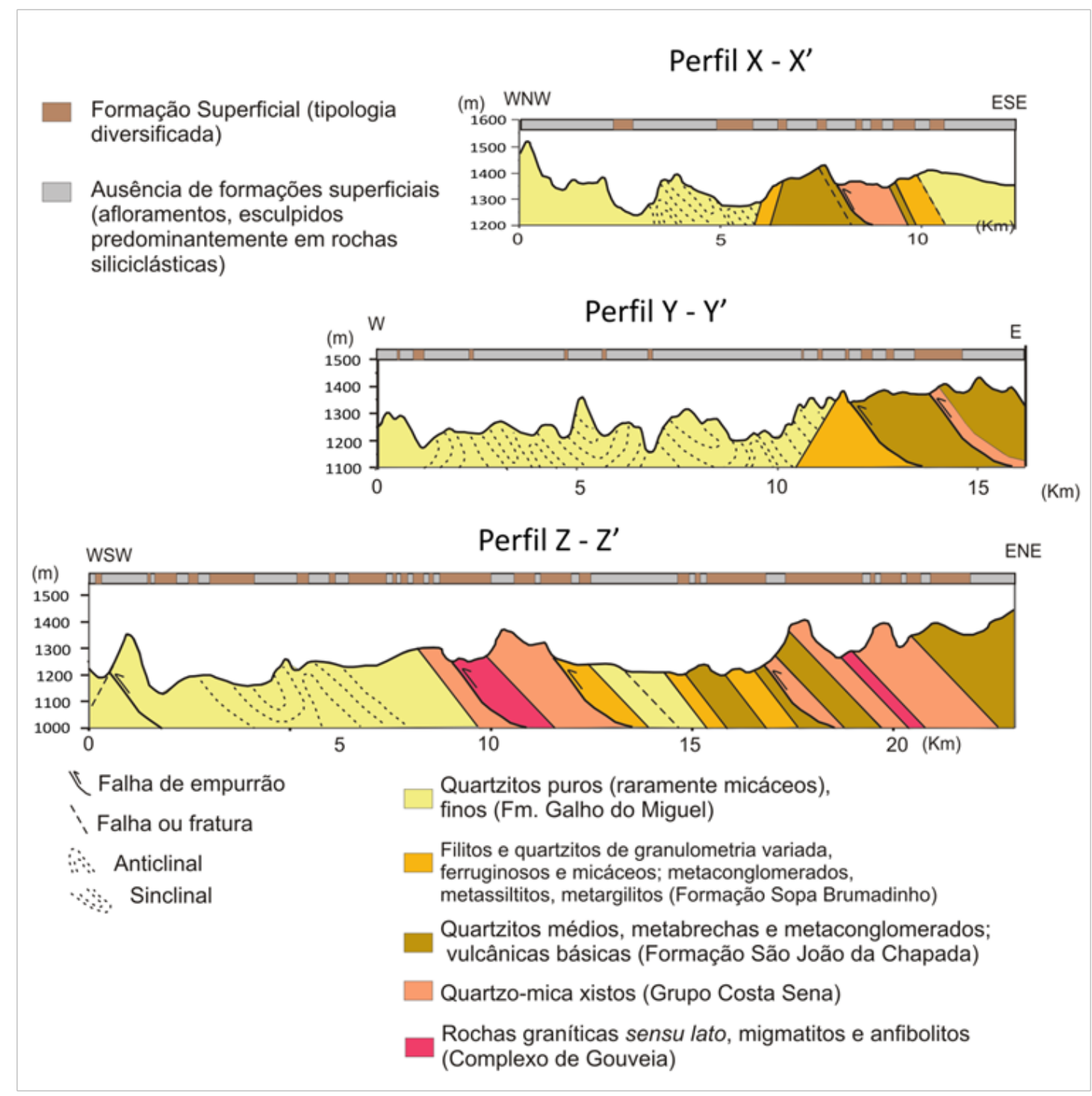

Fonte: Projeto Espinhaço, Comig, 1997

Autor: Simões, P. M. L. 


\section{CONSIDERAÇÕES FINAIS}

As extremidades leste e nordeste da área investigada têm sua configuração geomorfológica marcada pela elevada altitude e baixa dissecação. Essas ocorrem, principalmente, nas rochas das formações de São João da Chapada, Sopa Brumadinho e no Grupo Costa Sena. Essas áreas de maior altitude aparentemente são limitadas e, até mesmo, sustentadas pelas falhas de empurrões (Figura 05).

As áreas mais dissecadas, de menor altitude, se localizam na porção centro-oeste e sudoeste do alto curso do Rio Pardo Pequeno. Estas áreas são formadas basicamente pelos quartzitos da Formação Galho do Miguel, sendo caracterizadas pela presença de uma zona de sinclinais e de anticlinais.

A ocorrência das formações superficiais na área de estudo é influenciada pelas características litoestruturais da região. A maior concentração de afloramentos está na zona de sinclinais e anticlinais nas porções centro-leste e sudoeste, como pode ser observado nos perfis X-X' e Y-Y'. No perfil Z-Z' as formações superficiais ocupam área maior, contudo, na zona de sinclinais e anticlinais, a ocorrência dessas formações é mais restrita.

As formações superficiais se desenvolvem com maior expressão nas rochas do Grupo Costa Sena e Complexo Gouveia, devido a menor resistência aos processos intempéricos de tais litologias. Consequentemente, apresentam ocorrências menos significativas em áreas dos quartzitos da Formação Galho do Miguel.

A distribuição espacial das formações superficiais do alto curso do Rio Pardo Pequeno é fortemente controlada pelo arcabouço estrutural e pelo mosaico litológico que caracterizam o Planalto do Espinhaço Meridional. Adistribuição linear dessas formações está condicionada a feições estruturais diversas, notadamente falhas, falhas de empurrão, alinhamentos, anticlinais e sinclinais. Já as formações superficiais zonais são comandadas pelas diferenças entre a resistência das diversas rochas aos processos intempéricos.

Oestudosobreaconfiguraçãogeomorfológica do alto curso do Rio Pardo Pequeno deve considerar essas características das formações superficiais e os aspectos litoestruturais que estruturam a configuração geológica do Planalto do Espinhaço Meridional.

\section{REFERÊNCIAS}

ABREU, P. A. A. Supergrupo Espinhaço da Serra do Espinhaço Meridional (Minas Gerais): o Rifte, a Bacia e o Orógeno. GEONOMOS - Revista de Geociências, Belo Horizonte, vol. 3, n. 1, julho, 1995, pp. 1-18. DOI: 10.18285/geonomos.v3i1.211.

ABREU, P. A. A.; RENGER, F. E. Serra do Espinhaço Meridional: um orógeno de colisão do mesoproterozóico. Revista Brasileira de Geociência, Curitiba, vol. 32, n. 1, 2002, pp. 1-14.

BARBOSA, I. O.; LACERDA, M. P. C.; BILICH, M. R. Relações pedomorfogeológicas nas chapadas elevadas do Distrito Federal. Revista Brasileira de Ciência do Solo. Viçosa, v. 33, n. 5, 2009, pp. 13731383. DOI: 10.1590/S0100-06832009000500029.

CAMPY, M.; MACAIRE, J. J. Géologie des formations superficielles. Paris: Masson, 1989. 433p.

COMIG. Projeto Espinhaço. Belo Horizonte, Cia. Mineradora de Minas Gerais. (inclui 23 mapas geológicos na escala de 1:100.000), 1996. Disponível em: <http://www.comig.com.br/site/content/parcerias/ levantamento_aerogeofisico.asp?id=30\&idSubPrj $=50$ \&filhoId $=51>$.

DUSSIN, I.A.; DUSSIN, T.M. 1995. Supergrupo Espinhaço: Modelo de Evolução Geodinâmica. GEONOMOS - Revista de Geociências, Belo Horizonte, vol. 3, n. 1, 1995, pp. 31-39. DOI: http:// dx.doi.org/10.18285/geonomos.v3i1.212

FABRI, F.; AUGUSTIN, C. H. R. R.; AULER, A. S. Relevo cárstico em rochas siliciclásticas: uma revisão com base na literatura. Revista Brasileira de Geomorfologia, São Paulo, vol. 15, n. 3, 2014, pp. 339-351. DOI: 10.20502/rbg.v15i3.302.

INSTITUTO BRASILEIRO DE GEOGRAFIA E ESTATÍSTICA (IBGE). Diamantina, MG. Escala 
1:100.000. 1977.

KNAUER, L.G. $O$ Supergrupo Espinhaço em Minas Gerais: considerações sobre sua estratigrafia e seu arranjo estrutural. Revista de Geociências, Belo Horizonte, vol. 15, n. 1, 2007, pp. 81-63. DOI: 10.18285/geonomos.v15i1.109.

OLIVEIRA, F. V. C.; ALKMIM, F. F. Estilo estrutural e curvatura da porção sul do front do

Espinhaço. In: CONG. BRAS. GEOL., 38, Camboriú: 1994. Anais..., SBG, (2)259-260.

PATON, T. R. The Formation of Soil Material. London: George Allen \&Unwin, 1978. 143p.

RENGER, F. E.; KNAUER, L. G. Espinhaço Quo vadis? A evolução dos conhecimentos sobre a cordilheira do Espinhaço Meridional em Minas Gerais entre 1979 e 1995. GEONOMOS - Revista de Geociências, Belo Horizonte, vol. 3, n. 1, 1995, pp. 31-39. DOI: http://dx.doi.org/10.18285/geonomos. v3i1.214

REZENDE, E. A.; LEÃO, M. R.; SALGADO, A. A. R.; OLIVEIRA, C. K. R.; NALINI JÚNIOR, H. A. A influência litológica nas taxas de desnudação geoquímica do médio Espinhaço Meridional - MG. Sociedade e Natureza, Uberlândia, vol. 22, n. 3, 2010, pp. 503-5010.

DOI: $10.1590 /$ S1982-45132010000300007.

SAADI, A. A Geomorfologia da Serra do Espinhaço em Minas Gerais e de suas margens. GEONOMOS - Revista de Geociências, Belo Horizonte, vol. 3, n. 1, 1995, pp. 41-63. DOI: http://dx.doi.org/10.18285/ geonomos.v3i1.215

SALGADO, A. A. R.; VALADÃO, R. C. Contribuição da desnudação geoquímica na evolução da erosão diferencial no Espinhaço Meridional - MG. Revista Brasileira de Geomorfologia, São Paulo, Ano 4. n. 2, 2003, pp. 31-40. DOI: http://dx.doi.org/10.20502/ rbg.v4i2.22
SANTOS, E. C. Levantamento pedológico e perda geoquímica na Bacia do Rio Pardo Pequeno Espinhaço Meridional - Minas Gerais. 2012. 91f. Dissertação (Mestrado em Geografia) Universidade Federal de Minas Gerais - UFMG, Belo Horizonte, 2012.

THOMAS, M. F. Geomorphology in the tropics: study of weathering and denudation in low latitudes. New Jersey: Ed. Wiley, 1994. 460p.

YOUNG, R.; YOUNG, A. Sandstone Landforms. London: Springer-Verlag, 1992. 163p.

Soc. \& Nat., Uberlândia, 28 (1): 161-170, jan/abr/2016 